\title{
Every Cloud Has a Silver Lining: Lived Experience and Coping Strategies of Breast Cancer Survivors in Sarajevo
}

\author{
Nina Bosankic*, Selvira Draganovic ${ }^{\dagger}$, Jasmina Ramic ${ }^{\ddagger}$ \\ and Amber Haque
}

\begin{abstract}
This study explored how women breast cancer survivors who underwent radical mastectomy experienced stress and adversity and managed their diagnosis and treatment. This study is based on semi-structured and in-depth interviews with a convenience sample of 22 participants. Qualitative analysis and discussion groups were conducted in the participant's homes over 18 months. Thematic analysis resulted in four overarching categories that illustrated how the experience of being a woman was challenged and restructured from the participants' personal experiences. The participants" coping strategies were primarily reflected in their spirituality, optimism, an embrace of healthy lifestyles, and pink ribbon activism.
\end{abstract}

\section{Keywords}

breast cancer $\bullet$ Bosnia \& Hercegovina $\bullet$ spirituality $\bullet$ healthy lifestyle $\bullet$ Pink Ribbon Activism $\bullet$ Sarajevo $\bullet$ coping strategies

\section{Introduction}

Breast cancer is the most common type of cancer among women and one of the leading causes of cancer-related deaths worldwide (Ferlay et al., 2015; Denlinger et al., 2016; Miller et al., 2016). Available data suggest that in 2018, 2.1 million women were diagnosed with breast cancer globally (International Agency for Research on Cancer, 2018), and malignant diseases were among the leading causes of deaths in Bosnia and Herzegovina (B\&H; Federalni Zavod za Zdravstvo/ Federal Health Institute, 2012). The study on leading malignant diseases (bronchial, lungs, breast, colorectal) in B\&H between 2004 and 2010 indicated that $57 \%$ of such patients were diagnosed with some sort of malignant neoplasm and $25.1 \%$ were women with breast cancer (FederalniZavod za Zdravstvo/Federal Health Institute, 2012). The same study found that women between the ages of 50 and 70 years old had higher risks for developing breast cancer if a close family member was previously diagnosed with or treated for cancer or were diagnosed with any breast disease.

\footnotetext{
*International University of Sarajevo, nbosankic@ius.edu.ba

†International University of Sarajevo, sdraganovic@ius.edu.ba

¥International University of Sarajevo, jasmina.j.ramic@gmail.com

『Doha Institute for Graduate Studies, amberhaque@yahoo.com

Corresponding author: Amber Haque. Phone: +97466827819
}

doi: $10.3998 /$ jmmh.132

Conflicts of interest:

The authors have no conflicts of interest to disclose. 
The available data on cancer incidence in $\mathrm{B} \& \mathrm{H}$ in the Sarajevo region reported lung and breast cancer as the most common tumors, similar to neighboring Croatia and Slovenia (Obralić, 2005). The WHO country profile on cancer (2014) reported 1,152 cases (58.6\%) of breast cancer among women in B\&H. The International Agency for Research on Cancer by the World Health Organization (WHO, 2018) reported a $20.6 \%$ rate of new breast cancer cases in B\&H in 2018 (Globocan, 2018). The country has few radiology facilities and patient mammography appointments may take up to seven months, leading to prolonged diagnosis times and a lack of early detection. In B\&H, between 1,000 and 1,400 new cases of breast cancer are detected every year, but more than half of patients have metastases by the time they are diagnosed, and approximately 500 women die annually from breast cancer (Mehmedbašić, 2019).

The psychological and physical struggle of women with breast cancer may begin from diagnosis and continue during and after treatment (Al Azri, Al-Awisi, Al-Rasbi, \& Al-Moundhri, 2014). Patients face challenges at multiple stages. First, a cancer diagnosis is typically followed by severe psychological pressure such as shock, disbelief, and hope that the tests were wrong, which can lead to acute stress and apprehension (Arnaboldi et al., 2014; Carreira, Williams, Müller, Harewood, \& Bhaskaran, 2017). After diagnosis, a patient might also undergo a series of additional chronic and traumatic reactions (Al Azri et al., 2014; Voigt et al., 2017). Facing chronic stress and trauma when the body is already weak and vulnerable further complicates a patient's physical and psychological health. Additionally, cancer symptoms and deleterious treatment methods induce not only multiple physical problems and concerns but also emotional problems such as depression, anxiety, and distress (Boyes et al., 2013; Holland, 2013; Recklitis, Blackmon \& Chang, 2016).

Starting from the appearance of a tumor, breast cancer patients face other deleterious physiological and psychosocial effects, such as hot flashes, fatigue, uncertainty, peripheral neuropathy, existential distress, cognitive dysfunction, sleep disturbance, weakness, lymphedema, sexual dysfunction, financial concerns, debt, and weight changes. More than half of breast cancer survivors report experiencing these effects even 20 years after treatment concludes (Kenyon, Mayer, and Owens, 2014; Ness et al., 2013; Schmidt et al., 2012). Research also indicates that the most common concerns of breast cancer survivors are health status, femininity status (following surgical breast removal), job status (work interrupted by treatments and their side effects), fear of reoccurrence (Cohee et al., 2017), parenting and general roles within the family, uncertainty, anxiety, and the possibility of death (Ziner et al., 2012; Anusasananun, Linchong, Saipin, Pratum, \& Hongsin, 2013; Leal et al., 2015).

Serious physical and psychological problems caused by breast cancer require effective coping strategies (Casellas-Grau, Font \& Vives, 2014), which impact treatment outcome and survival rates of breast cancer survivors (Khalili, Farajzadegan, Mokarian, \&Bahrami, 2013). Sajadian and colleagues (2017) identify seven coping strategies commonly used by cancer patients after diagnosis, among which the most common are seeking social support, spirituality, and positive cognitive restructuring. However, survivor's use of coping strategies depends on the stage of cancer and therapy type, as well as individual factors such as personality, culture, and perception of disease; these are the issues affecting patient strategies to adjust and cope with this illness (Cebeci, Yangin \& Tekeli, 2012; Hopman \& Rijken, 2015). Given all this, it is important to identify breast cancer survivor coping strategies to develop and individually tailor efficient intervention strategies and improve their quality of life and survival.

Studies on this topic in $\mathrm{B} \& \mathrm{H}$ are minimal. While a few quantitative studies on breast cancer exploring the relationships between cancer and various sociodemographic and psychological variables are available in B\&H (Marijanovic, Pavlekovic, Buhovac \& Martinac, 2017; Salihbasic 
\& Delibegovic, 2018), there is no qualitative research into this topic. Although the mental and emotional responses to such significant life stress vary from person to person, it is crucial to listen and give survivors a voice. The objectives of this study were to explore the challenges of cancer survivors, identify coping skills, raise awareness, and discuss solutions. Specifically, this study examined issues of religiosity and institutional support that might ameliorate the participants' breast cancer coping experiences.

\section{Method}

\section{Participants}

The sample comprised 22 Bosnian Muslim women aged 29-41 years ( $M=35$, sd=6) who were diagnosed with breast cancer and underwent mastectomy and chemotherapy in the prior two years. The women were also active members of Renesansa and BolestNijeKraj, local NGOs helping breast cancer patients. Since the topic of the post-surgical body and illness-related traumatic experiences was rather sensitive, the first participant was recruited with the assistance of this association, followed by 12 more women recruited through snowball sampling. Also, a convenience sample of nine women was selected through the researchers' newly established personal contacts after the initial analysis of the first nine interviews. All participants were married, had children, and college or university degrees. Participation was voluntary and no material compensation was offered. Before the interviews started, the participants were informed about the study's intent and provided written informed consent.

\section{Procedure}

A total of 22 in-depth, semi-structured interviews were conducted in the participants' homes on two occasions over 18 months. The first two authors conducted the interviews as no special training was needed. Thematic analysis (TA) seemed most appropriate method since it "is not wed to any pre-existing theoretical framework" (Braun \& Clarke, 2006, p.9), and "is compatible with both essentialist and constructionist paradigms within psychology."(ibid, p.5) Thus, due to the data-led approach, TA allowed for the acknowledgment of women's subjective meanings as central to understanding their experiences as cancer survivors. Although a standard interview protocol was used, the participants were encouraged to be as open as possible. The interview lasted between 60 and 75 minutes and was interrupted only for brief periods when participants had emotional distress. The narratives were recorded and subsequently transcribed verbatim. The researchers discussed the data findings with participants over two months. Thematic analysis was performed using a six-phase method described by Nowell, Norris, White, and Moules (2017).

\section{Measures}

Semi-structured interviews allowed two-way communication between the interviewer and the participant and enabled the interviewer to learn answers to questions and the reasons for the answers. It enables digression from the main theme and the complexity of the studied subject can be better researched by investigating experiences and the meanings participants attach to them without limitations necessarily imposed by the structured interview (Seidman, 2006). A semi-structured interview protocol was created with nine open-ended questions (e.g., How did you feel when you first received the news? Did you have any support throughout the process and if not, how did you overcome it or find it?) and included three prompts. 


\section{Results}

More than 100 initial codes and approximately 20 themes emerged from the initial data analysis by two independent authors, which included familiarizing themselves with text and coding that was done in vivo and included abstract and generic codes that reflected the researchers' insights. The authors discussed discrepancies, consensus, and assigning codes via negotiation. A second-level analysis included reviewing, defining, and clustering the themes, which led to the formation of eight categories that were reduced to four overarching categories: "conceptualizing illness and an uncertain future," "less of a woman: questioning femininity," "every cloud has a silver lining," and "altruism or taking action." Particular attention was paid to categories that illustrated the "existential plight of cancer" and coping strategies challenged and restructured by the experience of a life-threatening diagnosis. The findings were then contrasted with the existing body of literature.

\section{Conceptualizing illness and an uncertain future}

The main category "conceptualizing illness and an uncertain future" was divided into two subcategories, "warning for (self) neglect," and "it's a new dawn, it's a new day."

\section{Warning for (self) neglect}

All the participants, in the same manner, underwent different phases, similar to the Kübler-Ross model (2014), with five stages of grief. To understand their illness, the subjects focused on the period before condition, questioning their behavior, decisions they had made, and relationships they had with other people, particularly their close relationships. This often triggered a feeling of guilt and caused them to blame themselves for their misfortune.

"I have always neglected myself, and I do think that this was a warning from God to stop doing that and look a little bit more on myself."(E., age 29)

\section{It's a new dawn; it's a new day}

Regardless of how desperate they were on occasion, they did not give up hope but instead mobilized healthy resources to cope, thus perceiving the diagnosis as a "second chance" of living life to its fullest and even a type of blessing. Their view on life changed dramatically, resulting in a new appreciation of life, so what used to be considered necessary or a source of daily stress was relativized and reduced to material, irrelevant, and ephemeral. All were grateful for every single day in their lives and for being able to "breathe in and feel the fresh air each morning." The treatment and recovery process was not easy, but for many, it was worth undergoing because it resulted in an appreciation of life, rediscovery of a true self, embracing a positive mindset, and living life to its fullest with their loved ones.

"The very fact of waking up every morning and realizing I am alive makes me grateful and improves my life daily." (M., age 39)

"I am grateful for this second chance. I would not say this is a punishment; it is a warning. I have been doing things for others, but now I know how to fight for myself, and I put myself in the first place. I neglected myself, but now I do not want to do that anymore." (E., age 38) 


\section{Less of a woman: Questioning femininity}

As amputation affects both physical and mental reality, the idea of the previous self was dramatically challenged after all the participants underwent radical mastectomy soon after being diagnosed with breast cancer. Only one had reconstructive surgery.

"Breasts are a symbol of femininity and a symbol of motherhood. It is one of the most beautiful attributes of a woman, and no one thinks about how a woman feels when she loses that symbol of femininity. She loses part of herself. I've arranged the surgery. I agreed to do the mastectomy, and that is a very difficult moment. Before I went to the hospital, I stood in front of the mirror to see my body (breasts) for the last time." (E., age 38)

The nature of femininity and loss was, and for some participants still is, one of their central issues, yet most of the subjects concluded that being a woman cannot be reduced to physical reality only and eventually accepted their loss. However, the removal of their breasts had no significant impact on their marital satisfaction or sexual life once they came to terms with the loss.

"I am no less valuable than some other woman. Regardless of all my scars, no matter how my body looks like, it's me." (A., age 38)

"I love you for who you are as a person, not for your body', he [patient's husband] said." (MTT, age 39)

However, one woman had difficulty accepting the loss of a part of her body.

"It is very hard for me to be intimate with my husband. I know it does not matter to him, but I still cannot look at myself in the mirror. I do not know if I will ever be able to accept the fact that my breast is not there anymore."(E., age 37)

\section{Every cloud has a silver lining}

The participants' coping strategies had three primary forms: sacred duty, religion and spirituality, and optimism and healthy lifestyles.

\section{Sacred duty}

All of the participants stressed that their spouses were supportive throughout the treatment and recovery process, and their relationship grew, more robust, and more meaningful, yet they drew the most strength from their children and parental obligations:

"I met an older lady at the hospital, and she told me, 'I must live for my grandchildren.' And then I looked at her, and it made me think. Her strength lies in her grandchildren, but what about me? I have two small children. I need to get them on the right path. I must be there for them. And this gave me the power and motivation to do something. It made me feel like I have to fight." (E., age 38)

"When I see how my son is growing up, that is enough for me."(A., age 38)

"I have a goal, seeing my beloved little girl growing up." (M., age 39) 
All participants insisted that the positive experiences with their husbands may have been more of an exception than the rule, as they often repeated that men were unable to stand by their wives during such a difficult life transition.

\section{Religion and spirituality}

During life-threatening events, the participants' belief in God helped them cope with adversities. Many found serenity in spirituality or religion. All stated that they had a profound spiritual experience during the treatment process and spirituality played an important role in coping. At the same time, for a few, it was the most important part of their life improvement. All of the participants also said that they had always believed, but it was only after the diagnosis and treatment that they felt more connected to God than they were before.

"We are born knowing that we will die. We all know that; we live with it. And we do not have time to cry." (E., age 39)

"One of the drastic changes is that I started wearing a hijab during my illness. People thought that it was because of my illness. However, that was just one of the reasons. But I would say that it is one more chance for a new life, and this had a great influence on me." (E., age 37)

\section{Optimism and embracing healthy lifestyles}

Faced with a life-threatening illness and an extremely invasive treatment, all of the participants rediscovered or adopted healthy lifestyles which significantly improved their quality of life. The strategies they used varied from becoming vigilant about a healthy balanced diet, getting enough sleep, and exercising as much as possible, to spending quality time with family and friends.

"I am trying as much as possible to avoid stress, negative people, and people who are burdening me with their own stories. I also went to see a psychologist, and it was very useful for me. So, everything was easy for me.” (E., age 38)

"I changed my eating habits dramatically. I did not want to feed my cancer." (E., age 37$)$

"I love my pets. The best therapist in the world has four paws and a big heart. For me, they are therapy. I feel good and relaxed with them. I also do decoupage." (E., age 38)

\section{Altruism or taking action}

One of the most striking themes was the need to help other women undergoing similar experiences and teach them to cope better, manage stress, and feel more in control of their illness. Being a breast cancer survivor who successfully managed to overcome life-threatening challenges came with the responsibility to help other women, be it in the form of raising awareness of early detection, advocacy, and lobbying for the procurement of drugs and equipment, or by merely showing compassion and support. By publicly sharing their narratives and providing comprehensive information, they wanted to destigmatize breast cancer and survival. 
"Only those who went through the whole process with breast cancer can fully understand other breast cancer survivors and their experiences. Only they can do it. They can understand all those feelings. An ordinary man cannot fully understand us." (E., age 38)

"I want to start my YouTube channel, so I talk about it openly, because there are so many women out there who need help and advice." (E., age 38)

I know so many women whose closest family members do not know anything about their struggle because they hide it. I want to encourage them to find time for themselves and take care of themselves. (E., age 39)

Five participants felt as if they were on an almost sacred quest; by sharing their personal information as survivors and supporting other women, they were, in part, redesigning their sense of purpose in life.

\section{Discussion}

This study confirmed recurrent themes in the participants' narratives about their initial diagnosis, including shock and disbelief, fear of death, uncertainty, ambiguity, and disintegration of life found in similar prior research. Previous studies showed that psychosocial distress, sometimes expressed as depression and anxiety in the period after diagnosis and treatment, were expressed more by younger women (Spencer et al., 1999; Avis, Crawford, \& Manuel, 2004; Sharpley \& Christie, 2007; Bantema-Joppe et al., 2015), which our study confirmed. The younger participants in our research vividly illustrated their narratives using negative emotions, self-blame, and internal causal attributions. Following Janoff-Bulman's (1992) hypothesis, self-blame resulted from primary stressors and not personality traits, meaning that the participants' distress levels, although significant, dealt with attribution of illness to factors outside the core self, providing a concrete sense of control and opportunities to change (Glinder\& Compass, 1999). The results of this study may seem contrary to other quantitative research (Glinder \& Compass, 1999; Bennett, Compass, Beckjord \& Glinder, 2005; Friedman et al., 2007) but this could have been due to the different methodological approaches used and because the participants were interviewed in the post-treatment period and not within the same year of diagnosis.

In the post-treatment period, with excellent social support provided by their families and friends, the participants started appreciating life more and reorganized their priorities, similar to several other reports (Morse, 1997; Drageset, Lindstrom, \& Underlid, 2010; Bozo, Gündoğdu, \& Büyükaşik-Çolak, 2009; Bahrami, Taleghani, Loripoor, \& Yousefy, 2015). Despite cancer, they managed to develop, grow, regain integrity, and adopt a new perspective on life. Another study that reviewed the findings of 14 articles on the experiences of breast cancer survivors also indicated that the development was seen as moving from actions toward healthier living and the renewal of values and priorities in life to the existential level of integrating and accepting death as well as ideas regarding spirituality and the meaning of life (Arman \&Rehnsfeldt, 2003).

Several studies of breast cancer survivors who underwent different types of surgery reported that satisfaction with post-surgical appearance was related to psychological wellbeing (Margolis, Goodman, Rubin \& Pajac, 1989; Al-Ghazal, Fallowfield, \& Blamey, 1999, 2000; Contant et al., 2004; Andersen, 2009). In a systematic literature review of breast cancer and psychosocial wellbeing, Helms, Hea, and Corso (2008) demonstrated that disturbed body image was related not only to lumpectomy or radical mastectomy but also to changes in body mass index (Lankester, Phillips, \& Lawton, 2002) and hair loss (Boehmke\& Dickerson, 2005). The participants in 
our study also noted several times that they were highly stressed to see their bodies after surgery. However, contrary to a study conducted by King and colleagues (2000) in which the negative impact of mastectomy on body image was highest among younger married women, in our study, all but one participant managed to embrace their new post-surgical physical and psychological self and restore femininity despite male imposed societal norms of beauty and femininity in the rather patriarchal Bosnian society. Also, all but one of our study's subjects reported no changes in the quality of their relationship with their partners and shared stories of their friends whose partners were not supportive or could not cope with either the physical or psychological changes the illness had caused, which was in line with the findings of Zahlis and Shands (1991).

All our study's participants reported fighting cancer as their sacred duty because of, as one said, in the necessity of "seeing my beloved little girl growing up." Having children might have been the source of finding meaning in their battle against cancer and required cognitive restructuring as an inevitable step people face when confronted with life-threatening situations. Finding the meaning in fighting cancer means reevaluating one's purpose and role in life. As one participant said, "illness helped me understand the importance and meaning of life," redefined their role as a parent and prioritized the child and his/her needs and care before their own, which was reflected in our participants' sacred duty to fight cancer. In their study, Elmberger, Bolund, and Lützen (2000) also reported that despite their battle, women found additional strength to transform their distress and continue being good parents as they considered it their moral duty.

To psychologically adjust to stressful situations, reduce emotional costs, and empower themselves, the participants used different coping strategies. Similar to a study by Siegel and Schrimshaw (2002) and earlier research by Koenig (1994), religion appeared to be a significant coping strategy for our subjects. During the interviews, all the participants stated that they considered themselves religious/spiritual, but (re)discovered and demonstrated even greater reliance on faith and adherence to religious/spiritual beliefs after their breast cancer diagnosis. Belief in a higher being and attributing religious significance to hardships helped the participants persevere through adversity. They managed to find deeper meaning in the suffering caused by cancer. This is in line with research that showed that positive religious coping could be a protective factor and is associated with better mental and emotional health and personal growth through adversity (Pargament et al., 1998; Ai, Peterson, \& Huang, 2003; Ai, Tice, Whitsett, Ishisaka, \&Chim, 2007; Pargament, Magyar-Russell, \& Murray-Swank, 2005). This positive religious coping defined as "an expression of a sense of self and spirituality" by Pargament and colleagues (2005) appeared to be a primary buffer against falling into despair in our study. One participant said, "spirituality was like a life-saving rope, it helped me get out safely after I had almost drowned."

Despite the adversity and distress of a stressful and life-threatening illness, of which the participants were highly aware, they remained optimistic. It was likely that their optimism was grounded in their innate positive self-perception and previous coping experiences. One of the significant characteristics of optimists is the use of active coping strategies and emphasizing the positive aspect of a difficult situation. This study's participants reported that facing a cancer diagnosis made them realize how neglectful they were toward themselves and was a wakeup call that shook them and reminded them to pay attention to themselves, live healthily, become vigilant about a healthy and balanced diet, get enough sleep, exercise as much as possible, and spend quality time with family and friends. Optimism as an explanatory lifestyle can also be related to cognitive reappraisal strategy, managing patients' interpretation of disease as an opportunity, a hint to change a life, and reflect upon what is essential in life, which may lead to reflection and setting new goals, changing aspects of life or behaviors, and seeing their situation as a chance for 
personal growth and transformation (Tedeschi \& Calhoun, 1995). Our study's participants also reported avoiding stress, negative people, seeking psychotherapeutic help, and enjoying pets, which affirmed their changed behavior as reflected in their optimistic attitudes.

Altruism is also a type of adaptive coping strategy and mature defense mechanism reflected in obtaining pleasure through the selfless desire to give what people themselves want to receive. The women in our study reported having an innate need to help other women undergoing the same experiences. They felt they were responsible for helping others by raising other women's awareness about their health, regular checkups, preventing diseases, sharing their experiences, and helping them "normalize," ameliorate, and manage their distress. Our participants' responsibility came in the form of acting selflessly by giving other women their previous experiences of fighting cancer. This could also be linked to the sacred duty of seeing the self in the quest to support, help save other women's lives, or even prevent breast cancer. Altruistic behaviors in the form of offering support to other women could increase women's empowerment and agency, which is a significant consequence of group support and consist of increased confidence and a sense of control in relation to the self, living with cancer, and interactions with others (Ussher et al., 2006).

Finally, empowerment can be achieved through different altruistic acts such as individual and group help and support, sharing their personal experiences and narratives privately and publicly, and providing comprehensive information that could also destigmatize (Klawiter, 2008) breast cancer and survival. Local breast cancer survivor activism is reflected in the local breast cancer associations Renesansa and BolestNijeKraj, which organize a local event called Šetajmozajedno u borbiprotiv carcinoma dojke (Race for the cure to fight breast cancer) held every year in September in different cities in $\mathrm{B} \& \mathrm{H}$ to raise awareness and help and support cancer survivors. Most of our study's participants volunteer for this organization.

The qualitative data obtained from this study provided profound insights into the lived experience of Bosnian women with breast cancer, cancer-related challenges, and coping. The study subjects always walked a thin line between hope and despair, conceptualized stress as a dichotomy of a deadly warning of self-neglect, and had a new chance to "seize the day."

Managing breast cancer calls for questioning femininity and the idea of the (previous) self that dramatically changed following radical mastectomy, called "less of a woman." The participants reported coping with cancer as their sacred duty through religion, spirituality, optimism, and healthy lifestyles that the authors categorized as "every cloud has a silver lining. "Altruism or taking action was the final theme, as all of the subjects identified an almost innate need to help other women cope better, manage stress, and feel more in control over illness. Breast cancer survivors who successfully overcame many life-threatening challenges seem to come with the responsibility to help other women be it in the form of increasing awareness of the importance of early detection, advocacy and lobbying for screening and early intervention, and the procurement of drugs and equipment, and by showing compassion and support. By publicly sharing their narratives and providing comprehensive information, they want to destigmatize breast cancer and survival. Hence, despite their adversities and distress, breast cancer survivors still manage to maintain hope, find meaning in life, and eventually utilize positive and active coping styles as manifested in their increased spirituality, optimism, embrace of healthy lifestyles, and pink ribbon activism.

Despite this study's positive findings, the sample was small, comprised of a homogenous group of young, heterosexual, married, and highly educated women living in the same city and actively involved with local breast cancer association, so the results cannot be generalized to larger target populations, even in Sarajevo. More research is needed to examine the challenges women of different ages and diverse socioeconomic backgrounds face and how they draw upon 
their strengths and from social support. Personal histories and contextual factors such as wars/post-war-related experiences, patriarchal societal norms and values, health reforms, political climates, and high unemployment rates should be considered in future research. A mixed-method study or triangulation would expand and strengthen this study's findings and conclusions.

All types of screening for breast cancer, such as breast self-exams, clinical breast examinations, and mammography, save lives, and a combination of cancer prevention, early detection, and better treatment can have a significant impact on incidence and mortality rates. However, unlike neighboring countries and the development of various legislation and policies, $\mathrm{B} \& \mathrm{H}$ does not have national breast screening programs, has limited numbers of mostly outdated mammogram machines, and very long hospital waiting lists. Therefore, nationwide awareness campaigns and mobile mammography units (used in Croatia since 2004 and in Serbia since 2018, but only in their capitals) can target more women and ensure a more rational utilization of existing health centers.

Despite these challenging circumstances and lack of institutional support, this study's participants demonstrated remarkable strength and initiative to destigmatize breast cancer and survival. Breast cancer survivors are initiating increased societal awareness, grassroots activities, and campaigns for digital mammograms. Those whose voices are not heard or are reluctant to join self-help groups can engage with health care providers. The local community and families should help implement preventive activities, mitigate the adverse consequences of illness and treatment, and enable smoother reintegration into society. Oncology departments must offer counseling to help patients reduce their problems and improve their quality of life by providing them psychological support.

\section{Acknowledgements}

The authors gratefully acknowledge the contributions of Neslihan Önal, Zişan Ergün, Sümeyye Nur Polat and İsra Yazgan

\section{References}

Ai, A. L., C. Peterson, \& B. Huang. (2003). The effect of religious-spiritual coping on positive attitudes of adult Muslim refugees from Kosovo and Bosnia. International Journal for the Psychology of Religion, 13(1), 29-47. https://doi.org/10.1207/S15327582IJPR1301_04

Ai, A. L., T.N. Tice, D. D. Whitsett, T. Ishisaka, \& M. Chim. (2007). Posttraumatic symptoms and growth of Kosovar war refugees: The influence of hope and cognitive coping. The Journal of Positive Psychology, 2(1), 55-65. https://doi.org/10.1080/17439760601069341

Al-Ghazal, S. K., Fallowfield, L. \& Blamey, RWW (1999). Does cosmetic outcome from treatment of primary breast cancer influence psychosocial morbidity? European Journal of Surgical Oncology, 25(6), 571-573. https://doi.org/10.1053/ejso.1999.0708

Al-Ghazal, S. K., Fallowfield, L. \& Blamey, RWW (2000). Comparison of psychological aspects and patient satisfaction following breast conserving surgery, simple mastectomy, and breast reconstruction. European Journal of Cancer, 36(15), 1938-1943. doi: 10.1016/s0959-8049(00)00197-0.

Andersen, B. L. (2009). In sickness and in health: maintaining intimacy after breast cancer recurrence. The Cancer Journal, 15(1), 70-73. doi: 10.1097/PPO.0b013e318198c742 
Anusasananun, B., P. Linchong, K. Saipin, Pratum, S. \& Hongsin. T. (2013). Coping behaviors and predicting factors among breast cancer survivors during each phase of cancer survivorship. Pacific Rim International Journal of Nursing Research,17(2), 148-166. Retrieved from https://he02.tcithaijo.org/index.php/PRIJNR/article/view/8285

Arman, M. \& Rehnsfeldt, A. (2003). The hidden suffering among breast cancer patients: A qualitative metasynthesis. Qualitative Health Research, 13(4), 510-527. Retrieved from http://urn.kb.se/ resolve?urn=urn:nbn:se:liu:diva-33674

Arnaboldi, P., Lucchiari, C., Santoro, L., Sangalli, C., Luini, A., \&Pravettoni, G. (2014). PTSD symptoms as a consequence of breast cancer diagnosis: Clinical implications. Springer Plus, 3(1), 1-7. doi: 10.1186/2193-1801-3-392

Avis, N. E., Crawford, S. \& Manuel, J. (2004). Psychosocial problems among young women with breast cancer. Psychooncology. 13(5), 295-308. doi: 10.1002/pon.744.

Bahrami, M., Taleghani, F. Loripoor, M. \& Yousefy, A. (2015). Positive changes after breast cancer: A qualitative study. Journal of Education and Health Promotion,4(1), 55. doi: $10.4103 / 2277-9531.162353$

Bantema-Joppe, E. J., Bock, G.H., Lersel, M., Busz, D.M., Ranchor, A.V., Langendijk, J.A., \& Heuvel, E.R. (2015). The impact of age on changes in quality of life among breast cancer survivors treated with breast-conserving surgery and radiotherapy. British Journal of Cancer, 112(4), 636-643. doi: $10.1038 / \mathrm{bjc} .2014 .632$

Bennett, K. K., Compass, B.E., Beckjord, E. \&Glinder, J.G. (2005). Self-blame and distress among women with newly diagnosed breast cancer. Journal of Behavioral Medicine, 28 (4), 313-323. https://doi.org/10.1007/s10865-005-9000-0

Boehmke, M. M., \& Dickerson, S. S. (2005). Symptom, symptom experiences, and symptom distress encountered by women with breast cancer undergoing current treatment modalities. Cancer Nursing, 28(5), 382-389. doi: 10.1097/00002820-200509000-00008.

Boyes, A. W., Girgis, A., D’Este, C. A., Zucca, A. C., Lecathelinais, C., \& Carey, M. L. (2013). Prevalence and predictors of the short-term trajectory of anxiety and depression in the first year after a cancer diagnosis: a population-based longitudinal study. Journal of Clinical Oncology, 31(21), 2724-2729. doi: 10.1200/jco.2012.44.7540

Bozo, Ö., Gündoğdu, E. \&Büyükaşik-Çolak, C. (2009). The moderating role of different sources of perceived social support on the dispositional optimism - posttraumatic growth relationship in postoperative breast cancer patients. Journal of health psychology, 14(7), 1009-1020. doi: 10.1177/1359105309342295.

Carreira, H., Williams, R., Müller, M. Harewood, R., \&Bhaskaran, K.(2017). Adverse mental health outcomes in breast cancer survivors compared to women who did not have cancer: systematic review protocol. Systematic Reviews, 6, 162. https://doi.org/10.1186/s13643-017-0551-2

Casellas-Grau, A., Font, A., \& Vives, J. (2014). Positive psychology interventions in breast cancer. A systematic review. Psychooncology, 23(1), 9-19. doi: 10.1002/pon.3353

Cebeci, F., Yangin, H. B., \&Tekeli, A. (2012). Life experiences of women with breast cancer in southwestern Turkey: A qualitative study. European Journal of Oncology Nursing, 16(4), 406-412. doi: 10.1016/j.ejon.2011.09.003.

Cohee, A.A., Adams, R.N., Johns, S.A., Von, A.D., Zoppi, K., Fife, B., Monahan, P.O., Stump, T., Cella, D., \& Champion, VLL (2017-5). Long-term fear of recurrence in young breast cancer survivors and partners. Psychooncology, 26(1), 22-28. doi: 10.1186/s41687-020-0184-4 
Contant, C. M. E., van Wersch, A.M.E., Menke-Pluymers, M.B.E., Tjong-Joe-Wai, R., Eggermont, A.M.M. \& van Geel, ANN (2004). Satisfaction and prosthesis related complaints in women with immediate breast reconstruction following prophylactic and oncological mastectomy. Psychology, Health E Medicine, 9(1), 71-84. https://doi.org/10.1080/13548500310001637760

Denlinger, C. S., Ligibel, J. A., Are, M., Baker, K. S., Broderick, G., Demark-Wahnefried, W.\& Ku, G. H. (2016). NCCN guidelines insights: survivorship, version 1.2016. Journal of the National Comprehensive Cancer Network, 14(6), 715-724. doi: 10.6004/jnccn.2016.0073.

Drageset, S, Lindstrom, T.C. \& Underlid, K. (2010-9). Coping with breast cancer: between diagnosis and surgery. Journal of Advanced Nursing, 66(1), 149-158. https://doi.org/10.1111/j.13652648.2009.05210.x

Elmberger, E., Bolund, C. \&Lützen, K. (2000). Transforming the exhausting to energizing process of being a good parent in the face of cancer. Health Care Women International, 21(6), 485-499. doi: $10.1080 / 07399330050130287$.

FederalniZavod za javnozdravstvo B\&H (2012). Izvještaj: Pregled Malignih Neoplazmi U BiH Retrieved from http://www.zzjzfbih.ba/wpcontent/uploads/2014/04/Pregled-malignihneoplazmi-2012.pdf

Ferlay, J., I. Soerjomataram, R. Dikshit, S. Eser, C. Mathers, M. Rebelo, D. M. Parkin, D. Forman, and F. Bray. 2015. Cancer incidence and mortality worldwide: sources, methods and major patterns in GLOBOCAN 2012. International journal of cancer 136 (5). doi: 10.1002/ijc.29210

Friedman, L. C., Romero, C., Elledge, R. Chang, J., Kalidas, M. Dulay, M.F. \& Osborne, C.K. (2007). Attribution of blame, self-forgiving attitude and psychological adjustment in women with breast cancer. Journal of Behavioral Medicine, 30(4), 351-357. doi: 10.1007/s10865-007-9108-5

Glinder, J G., \& Compass, BEE (1999). Self-blame attributions in women with newly diagnosed breast cancer: A prospective study of psychological adjustment. Health Psychology, 18(5), 475-481. https://doi.org/10.1037/0278-6133.18.5.475

Globocan (2018). Global Cancer Observatory, International Agency for Research on Cancer by the World Health Organization, report on Bosnia and Hercegovina. Retrieved from https://gco.iarc. $\mathrm{fr} /$ today/data/factsheets/populations/70-bosnia-and-herzegovina-fact-sheets.pdf

Helms, R. L., O’Hea, E.L. \& Corso, M. (2008). Body image issues in women with breast cancer. Psychology, Health and Medicine,13(3), 313-325. doi: 10.1080/13548500701405509.

Holland, J. C., Andersen, B., Breitbart, W. S., Buchmann, L. O., Compas, B., Deshields, T. L., et al. (2013). Distress Management: Clinical practice guidelines in oncology. JNCCN Journal of the National Comprehensive Cancer Network, 11(2), 190-209. https://doi.org/10.6004/ jnccn.2013.0027

Hopman, P., \&Rijken, M. (2015). Illness perceptions of cancer patients: relationships with illness characteristics and coping. Psychooncology, 24(1), 11-18. doi: 10.1002/pon.3591.

International Agency for Research on Cancer, IARC release latest world cancer statistics. (2020, August 3). Retrieved from https://www.uicc.org/news/iarc-release-latest-world-cancer-statistics

Janoff-Bulman, R. (1992). Shattered assumptions: Towards a new psychology of trauma. New York: Free Press.

Kenyon, M., Mayer, D. K., \& Owens, A. K. (2014). Late and long-term effects of breast cancer treatment and surveillance management for the general practitioner. Journal of Obstetric, Gynecologic \& Neonatal Nursing, 43(3), 382-398. doi: 10.1111/1552-6909.12300. 
Khalili, N., Farajzadegan, Z., Mokarian, F., \&Bahrami, F. (2013). Coping strategies, quality of life and pain in women with breast cancer. Iranian journal of nursing and midwifery research, 18(2), $105-111$.

King, M. T., Kenny, P., Shiell, A.J., Hall, J. \& Boyages, J. (2000). Quality of life three months and one year after first treatment for early stage breast cancer: influence of treatment and patient characteristics. Quality of Life Research, 9(7), 789-800. doi: 10.1023/a:1008936830764.

Klawiter, M. (2008). The biopolitics of breast cancer: Changing cultures of disease and activism. University of Minnesota Press.

Koenig, H. G. (1994). Aging and God: Spiritual pathways to mental health in midlife and later years. Binghamton, New York: Haworth Pastoral Press.

Kübler-Ross, E., \& Kessler, D. (2014). On grief and grieving: Finding the meaning of grief through the five stages of loss. Simon and Schuster.

Lankester, K. J., Phillips, J.E. \& Lawton. PAA (2002). Weight gain during adjuvant and neoadjuvant chemotherapy for breast cancer: An audit of 100 women receiving FEC or CMF chemotherapy. Clinical Oncology, 14(1), $64-67$.

Leal, I., Engebretson, J. Cohen, L., Rodriguez, A. Wangyal, T., Lopez, G. \&Chaoul, A. (2015). Experiences of paradox: a qualitative analysis of living with cancer using a framework approach. Psychooncology, 24(2), 138-146. doi: 10.1002/pon.3578.

Margolis, G J., Goodman, R.L., Rubin, A. \&Pajac, TFF (1989). Psychological factors in the choice of treatment for breast cancer. Psychosomatics, 30(2), 192-198. doi: 10.1016/S0033-3182(89)72300-8.

Marijanović, I., Pavleković, G., Buhovac, T., \& Martinac, M. (2017). The relationship between health locus of control, depression, and sociodemographic factors and amount of time breast cancer patients wait before seeking diagnosis and treatment. Psychiatria Danubina, 29(3), 330-344.

Mehmedbasić, S. (2019). Oktobar / Listopadmjesecborbeprotivkarcinomadojke. Retreived from https://mehmedbasic.ba/oktobarlistopad-mjesec-borbe-protiv-karcinoma-dojke/

Miller, K. D., Siegel, R. L., Lin, C., Mariotto, C. Kramer, A.B., Rowland, J.L., Stein., J.H., Alteri, K.D., \& Jemal, R. (2016). Cancer treatment and survivorship statistics. Cancer Journal for Clinicians, 66(4), 271-289. doi: 10.3322/caac.21349.

Morse, J. M. (1997). Responding to threats to integrity of self. Advanced Nursing Science, 19(4), 21-36. doi: 10.1097/00012272-199706000-00003.

Ness, K. K., Jones, K.E., Smith, W.A., Spunt, S.L., Wilson, C.L., Armstrong, G.T., et al. (2013). Chemotherapy-related neuropathic symptoms and functional impairment in adult survivors of extracranial solid tumors of childhood: results from the St. Jude Lifetime Cohort Study. Archives of Physical Medicine and Rehabilitation, 94(8), 1451-1457. doi: 10.1016/j.apmr.2013.03.009.

Nowell, L. S., Norris, J.M., White, D.E., \& Moules, NJ. (2017). Thematic Analysis: Striving to Meet the Trustworthiness Criteria. International Journal of Qualitative Methods, 16(1). https://doi. org/10.1177/1609406917733847

Obralić, N. (2005). Cancer incidence in Sarajevo region. MedicinskeArbive, 59(4), 250-254.

Pargament, K. I., Magyar-Russell, G.M. \& Murray-Swank, N.A. (2005).The sacred and the search for significance: Religion as a unique process. Journal of Social Issues, 61(4), 665-687. https://doi. org/10.1111/j.1540-4560.2005.00426.x 
Pargament, K. I., Smith, B. W., Koenig, H.G., and Perez, L. (1998). Patterns of positive and negative religious coping with major life stressors. Journal for the Scientific Study of Religion,37 (4), 710724. https://doi.org/10.2307/1388152

Recklitis C.J., Blackmon JE, Chang G. (2016). Screening young adult cancer survivors for distress with the Distress Thermometer: Comparisons with a structured clinical diagnostic interview. Cancer. 122(2),296-303. doi: 10.1002/cncr.29736.

Sajadian, A., RajiLahiji, M., Motaharinasab, A., Kazemnejad, A., \&Haghighat, S. (2017). Breast cancer coping strategies after diagnosis: A six-month follow-up. Multidisciplinary Cancer Investigation, 1(4), 12-16.

Salihbasic, M., \&Delibegovic, S. (2018). The Quality of Life and Degree of Depression of Patients Suffering from Breast Cancer. Medical archives, 72(3), 202-205. doi: 10.5455/medarh.2018.72.202-205.

Schmidt, M. E., Chang-Claude, J., Vrieling, A., Heinz, J. Flesch-Janys, D. \& Steindorf, K. (2012). Fatigue and quality of life in breast cancer survivors: temporal courses and long-term pattern. Journal of Cancer Survivorship,6(1), 11-19. doi: 10.1007/s11764-011-0197-3.

Seidman, I. (2006). Interviewing as qualitative research: a guide for researchers in education and the social sciences. $3^{\text {rd }}$ ed. New York: Teachers College Press.

Sharpley, C. F., \& Christie, D.R.H. (2007). How I was then and how I am now': current and retrospective self-reports of anxiety and depression in Australian women with breast cancer. PsychoOncology, 16(8), 752-762.

Siegel, K., \&Schrimshaw, E.W. (2002). The perceived benefits of religious and spiritual coping among older adults living with HIV/AIDS. Journal for the Scientific Study of Religion, 41 (1), 91-102.

Spencer, S. M., Lehman, J.M., Wynings, C., Arena, P., Carver, C.S., Antoni, M.H. \& Love, N. (1999). Concerns about breast cancer and relations to psychosocial well-being in a multiethnic sample of early-stage patients. Health Psychology.18(2), 159-168. doi: 10.1037//0278-6133.18.2.159.

Tedeschi, R. G., \& Calhoun, L. G. (1995). Trauma E transformation: Growing in the aftermath of suffering. Sage Publications, Inc.

Ussher, J., L. Kirsten, P. Butow, and M. Sandoval. (2006). What do cancer support groups provide which other supportive relationships do not? The experience of peer support groups for people with cancer. Social science E Medicine.62(10), 2565-2576.

Voigt V., Neufeld F., Kaste J., Bühner M., Sckopke P., Wuerstlein R., et al. 2017. Clinically assessed posttraumatic stress in patients with breast cancer during the first year after diagnosis in the prospective, longitudinal, controlled COGNICARES study. Psychooncology, 26(1), 74-80. doi: 10.1002/pon.4102.

World Health Organization (2014). Cancer country profiles 2014. Retrieved from https://www.who. int/cancer/country-profiles/en/

World Health Organization (2018). Cancer key facts. Retrieved from https://www.who.int/news-room/ fact-sheets/detail/cancer

Zahlis, E. H., \&Shands, M.E. (1991). Breast cancer: Demands of the illness on the patient's partner. Journal of Psychosocial Oncology,9(1), 75-93.

Ziner, K. W., G. W. Sledge Jr., C. J. Bell, S. Johns, K. D. Miller, \& V. L. Champion (2012). Predicting fear of breast cancer recurrence and self-efficacy in survivors by age at diagnosis. Oncology Nursing Forum. 39(3), 287-295. doi: 10.1188/12.ONF.287-295. 